\title{
BMJ Open Use of high doses of folic acid supplements in pregnant women in Spain: an INMA cohort study
}

Eva María Navarrete-Muñoz, ${ }^{1,2}$ Desirée Valera-Gran, ${ }^{1}$ Manoli García de la Hera, ${ }^{1,2}$ Daniel Gimenez-Monzo, ${ }^{1}$ Eva Morales, ${ }^{2,3}$ Jordi Julvez, ${ }^{2,3}$ Isolina Riaño, ${ }^{2,4}$ Adonina Tardón, ${ }^{2,5}$ Jesus Ibarluzea, ${ }^{2,6,7}$ Loreto Santa-Marina, ${ }^{2,6,7}$ Mario Murcia,, ${ }^{2,8}$ Marisa Rebagliato, ${ }^{2,9}$ Jesus Vioque, ${ }^{1,2}$ on behalf of the INMA Project

To cite: Navarrete-

Muñoz EMía, Valera-Gran D, García de la Hera M, et al. Use of high doses of folic acid supplements in pregnant women in Spain: an INMA cohort study. BMJ Open 2015;5:e009202.

doi:10.1136/bmjopen-2015009202

- Prepublication history for this paper is available online. To view these files please visit the journal online (http://dx.doi.org/10.1136/ bmjopen-2015-009202).

Received 25 June 2015 Revised 22 October 2015 Accepted 23 October 2015

CrossMark

For numbered affiliations see end of article.

Correspondence to Professor Jesús Vioque López; vioque@umh.es

\section{ABSTRACT}

Objectives: We examined the use of low $(<400 \mu \mathrm{g} /$ day, including no use) and high folic acid supplement (FAS) dosages ( $\geq 1000 \mu \mathrm{g} /$ day) among pregnant women in Spain, and explored factors associated with the use of these non-recommended dosages.

Design: Population-based cohort study.

Setting: Spain.

Participants: We analysed data from 2332 pregnant women of the INMA study, a prospective mother-child cohort study in Spain.

Main outcome measures: We assessed usual dietary folate and the use of FAS from preconception to the 3rd month (first period) and from the 4th to the 7th month (second period), using a validated food frequency questionnaire. We used multinomial logistic regression to estimate relative risk ratios (RRRs).

Results: Over a half of the women used low dosages of FAS in the first and second period while $29 \%$ and $17 \%$ took high dosages of FAS, respectively. In the first period, tobacco smoking ( $R R R=1.63)$, alcohol intake ( $R R R=1.40)$, multiparous ( $R R R=1.44)$, unplanned pregnancy $(R R R=4.20)$ and previous spontaneous abortion (RRR $=0.58$, lower use of high FAS dosages among those with previous abortions) were significantly associated with low FAS dosages. Alcohol consumption ( $R R R=1.42)$, unplanned pregnancy $(R R R=2.66)$ and previous spontaneous abortion (RRR $=0.68$ ) were associated with high dosage use. In the second period, only tobacco smoking was significantly associated with high FAS dosage use (RRR=0.67).

Conclusions: A high proportion of pregnant women did not reach the recommended dosages of FAS in periconception and a considerable proportion also used FAS dosages $\geq 1000 \mu \mathrm{g} /$ day. Action should be planned by the Health Care System and health professionals to improve the appropriate periconceptional use of FAS, taking into consideration the associated factors.

\section{BACKGROUND}

The benefits of periconceptional use of folic acid supplements (FAS) to prevent neural tube defects (NTDs) have been well
Strengths and limitations of this study

- We assessed dietary folate intake and folic acid supplement, using a validated food frequency questionnaire in pregnant Spanish women.

- This was a population-based cohort study.

- Participation rates were not high and nonparticipation might limit the generalisation of some results.

established since the early 1990s. ${ }^{1}{ }^{2}$ Health authorities recommend that all women who plan to become pregnant should take a daily dose of $400 \mu \mathrm{g}$ FAS and appropriate dietary folate intake from before conception to the third month of pregnancy to reduce the risk of NTDs, while not exceeding the tolerable upper intake level of $1000 \mu \mathrm{g} /$ day. ${ }^{3}$ An exception is made for those women with diabetes, epilepsy and history of NTDs, who are recommended to take a daily dose of $5000 \mu \mathrm{g} \mathrm{FAS.}{ }^{4}$ Although FAS are safe and almost free of toxicity, a few studies have drawn attention to the possible adverse effects of using high doses throughout pregnancy $^{5-8}$ and at other stages of life. ${ }^{9}$

The interest in the health implications of taking FAS has increased recently. Regarding pregnancy, several studies have suggested that FAS use may be an important protective factor for some birth outcomes such as placental abruption, spontaneous abortion, stillbirth, preterm delivery, adverse fetal growth and preeclampsia. ${ }^{10}{ }^{11}$ FAS use during pregnancy has been also associated with protection against impaired neurodevelopment, ${ }^{12} 13$ but we have recently observed that FAS dosages above the recommendation might affect psychomotor development at 1 year of age. ${ }^{8}$ Several studies have found a relationship between FAS and allergic disorders or asthma in childhood, ${ }^{14}$ although a recent meta-analysis does not provide a conclusive 
association. ${ }^{15}$ Although FAS might reduce the risk of several harmful pregnancy outcomes and childhood problems, many questions still remain open on the potential effects of using high dosages of FAS at different periods during pregnancy.

In this sense, most studies have focused on monitoring dietary folate intake and FAS in the periconceptional period, ${ }^{16-19}$ and only a few have assessed the use of FAS after the time period around neural tube closure. ${ }^{20}$ Thus, research into maternal folate intake and the use of high dosages of FAS during pregnancy is necessary for the clarification of the possible effects in birth outcomes and in childhood health. ${ }^{12-15}$ In this study, we use data from pregnant women participating in a multicentre prospective mother-child cohort study in Spain, to examine the use of low (non-use and $<400 \mu \mathrm{g} /$ day) and high dosages $(\geq 1000 \mu \mathrm{g} /$ day $)$ of FAS in pregnant women in Spain from 3 months before conception to the third month of pregnancy and from the fourth to seventh month of pregnancy. We also explore factors associated with the use of these low and high dosages of FAS in the two periods.

\section{MATERIALS AND METHODS Population}

We use data from 2332 pregnant women recruited in the multicentre population-based mother-child cohort INMA Project (INfancia y Medio Ambiente (Childhood and Environment)) between 2003 and 2008 in four different regions of Spain with a common protocol: Valencia, Sabadell (Catalonia), Asturias and Guipuzcoa (Basque Country). ${ }^{21}$ Women were enrolled during their first antenatal care visit to the main public hospital or health centre of reference. A total of 2644 women who fulfilled the inclusion criteria $(\geq 16$ years old, singleton pregnancy, intention to deliver at the reference hospital, no communication handicap and no assisted pregnancy) agreed to participate. Excluding the women who withdrew from the study, those lost to follow-up and those who had an induced or spontaneous abortion, or who had fetal deaths $(n=138)$, a total sample of 2506 women delivered a live infant between May 2004 and August 2008. After excluding participants with missing data for relevant variables, $2332(93.1 \%)$ were included in the present analysis. All participants provided informed consent, and the ethics committees of the centres involved in the study approved the research protocol.

\section{Study variables}

\section{Assessment of dietary folate intake and FAS use}

FAS and dietary folate were retrospectively assessed by personal interviews at two time points in pregnancy: at 10-13 weeks and at 28-32 weeks; more details about these intakes were described previously. ${ }^{22}$ Dietary folate intake was determined using a 101-item, semiquantitative food frequency questionnaire $(\mathrm{FFQ})$, covering intakes in two periods. The first period included intakes from the last menstrual period until the third month of pregnancy, and the second period covered intakes from the fourth month to the seventh month of pregnancy. The FFQ was an adapted version of the Willett questionnaire, ${ }^{23}$ validated and developed for Spanish pregnant women in Valencia. ${ }^{24}$ In a validation study of the FFQ carried out within the same population of pregnant women in the third month of pregnancy, the correlation coefficient between serum folate and the intake of dietary folate and FAS was satisfactory, $r=0.53(p<0.001){ }^{24}$

Folate content of food items was primarily obtained from food composition tables of the US Department of Agriculture $^{25}$ and other tables published for Spanish foods. ${ }^{26}$ In Spain, folate fortification is not mandatory, thus we obtained the folate content of foods from nonfortified foods; except for cereals, owing to the main brands usually fortifying them. The consumption level of FAS or vitamin/mineral preparations containing FAS was collected using a structured questionnaire. FAS were estimated based on supplement brand name and composition, daily dose and timing of consumption. There were three main sources of FAS in Spain: specific single folic acid preparations with content from $400 \mu \mathrm{g}$ (Zolico) to $10000 \mu \mathrm{g}$ (ASPOL); supplements of levofolinate or calcium folinate with content between $2500 \mu \mathrm{g}$ (Folaxin 2.5®) and $15000 \mu \mathrm{g} /$ day (Lederfoli); and multivitamins with folic acid content between $75 \mu \mathrm{g}$ (Calcinaralobs) and $1000 \mu \mathrm{g}$ (Gestamater). With this information, mean daily FAS intake was estimated as the mean of FAS intake in two periods: the first period included the information of FAS from 3 months before conception to the third month of pregnancy (interview at 10-13 weeks) and the second period included the information of FAS from fourth to seventh month of pregnancy (interview at 28-32 weeks). FAS intake in the two periods was classified into three categories: $<400$ (including no use), 400-999 and $\geq 1000 \mu \mathrm{g} /$ day.

\section{Covariates}

Information on covariates was obtained from questionnaires completed by personal interviews in the first and third trimester of pregnancy. The sociodemographic characteristics considered were: maternal age, maternal and paternal education level (primary school or less, secondary school and university studies), lifestyle variables such as tobacco smoking (yes or no), alcohol consumption (yes or no) in the first trimester of pregnancy, and self-reported pre-pregnancy body mass index calculated in $\mathrm{kg} / \mathrm{m}^{2}$ and classified as <25, 25-29.9 (overweight) and $\geq 30$ (obesity). Relevant data about obstetrics such as number of previous pregnancies $(0$ and $\geq 1$ ), unplanned pregnancy (yes or no), previous abortion (yes or no) and visiting a private gynaecologist in the first trimester (yes or no) were also collected.

\section{Statistical analysis}

Descriptive analysis of sociodemographic, lifestyle and obstetric characteristics of the pregnant women was 
performed for the four areas of study. We also described the dietary folate and FAS intake overall and by geographical area using geometrical mean, mean and SDs. We used the analysis of variance test for quantitative variables and the $\chi^{2}$ test for qualitative variables.

Predictors of the use of low $(<400 \mu \mathrm{g} /$ day, including non-users $)$ and high $(\geq 1000 \mu \mathrm{g} /$ day $)$ dosages of FAS from preconception to the third month, from the fourth to the seventh month of pregnancy and in the entire pregnancy were explored using multivariate multinomial logistic regression (relative risk ratio: RRR): low-dose or high-dose categories were compared to the recommended dose (400-999 $\mu \mathrm{g} /$ day) adjusted for all other covariates by study areas. We used meta-analysis to obtain combined estimates for the four cohorts. Heterogeneity was quantified by means of the $\left(\mathrm{I}^{2}\right)$ statistic and $\mathrm{p}$ value of heterogeneity test. ${ }^{27}$ With levels above $50 \%$, the random-effects model was applied to obtain combined estimates and the fixed effect meta-analysis model when $\mathrm{I}^{2}<50 \%$. Statistical analyses were conducted with $\mathrm{R} 3.0 .0$ (R Foundation for Statistical Computing, Vienna, Austria; http://www.r-project.org).

\section{RESULTS}

Table 1 shows the sociodemographic, lifestyle and obstetric characteristics of the pregnant women. Significant differences among geographical areas were observed for most variables although not for parity and previous abortions. Half of the pregnant women were above 30 years of age (Asturias showed the highest proportion, 59.7\%, and Valencia the lowest proportion, $43.2 \%$ ). Of the women, $34.4 \%$ reported having pursued university studies. Tobacco smoking and alcohol consumption during the first trimester of pregnancy were reported by $18.1 \%$ and $29.9 \%$ of the women, respectively. The prevalence of pre-pregnancy obesity was $8.0 \%$. A total of $16.7 \%$ of pregnancies were unplanned and previous abortions were reported by $23.5 \%$ of the women.

The mean daily folate intake was similar in the two periods of pregnancy, 307.8 and $304.7 \mu \mathrm{g} /$ day, respectively. The main food group sources of dietary folate intake among the pregnant women in both periods of pregnancy were vegetables $(22.8 \%)$, fruits $(15.7 \%)$, legumes $(10.5 \%)$, dairy products $(8.6 \%)$ and cereals/ pasta $(7.0 \%)$. Individually, the major contributing foods to dietary folate intake were legumes $(10.5 \%)$, lettuce $(8.4 \%)$, oranges $(5.5 \%)$, bread $(5.5 \%)$ and cereals $(5.5 \%)$.

Figure 1 shows the proportion of women using FAS during pregnancy. The percentage of women using FAS in preconception, the first, second and third month of pregnancy was $22.8 \%, 30.4 \%, 57.4 \%$ and $85.8 \%$, respectively. The proportion of women using FAS in the periconceptional period was similar in the four geographical areas although significant differences were noted afterwards: women in Valencia and Asturias continued using FAS after the third month ( $84 \%$ and $95 \%$, respectively), while most women in Guipuzcoa and Sabadell stopped (approximately 10\% continued). Overall, 149 of the women did not take FAS at any time during pregnancy; most were from Sabadell and Guipuzcoa (89\%). Considering the entire pregnancy, approximately one-third of the women reported the use of high dosages of FAS $(\geq 1000 \mu \mathrm{g} /$ day $)$, although this proportion varied by geographical area: Asturias and Guipuzcoa showed higher percentages of women using FAS dosages $\geq 1000 \mu \mathrm{g} /$ day than women from Sabadell and Valencia (data not show). The major sources of high dosages of FAS $(\geq 1000 \mu \mathrm{g} /$ day $)$ were specific single folic acid preparations such as ACFOL (5000 $\mu \mathrm{g} /$ day) or ASPOL $(10000 \mu \mathrm{g} /$ day $)$.

Overall, during the periconceptional stage, $57 \%$ of pregnant women used low FAS dosages $(<400 \mu \mathrm{g} /$ day, including no use), and $29 \%$ of women used high FAS dosages $(\geq 1000 \mu \mathrm{g} /$ day $)$. In this period, the mean daily intake of FAS was $433.0 \mu \mathrm{g} /$ day for women classified as taking FAS dosages of 400-999 $\mu \mathrm{g} /$ day, $141.8 \mu \mathrm{g} /$ day for women taking FAS dosages $<400 \mu \mathrm{g} /$ day and 3104.6 for women taking dosages of $\geq 1000 \mu \mathrm{g} /$ day. Table 2 shows multivariate analyses for all the cohorts combined, in the first period. Tobacco smoking (RRR=1.63) and alcohol intake $(\mathrm{RRR}=1.40)$ in the first trimester of pregnancy, unplanned pregnancy ( $R R R=4.20)$, previous pregnancies $(R R R=1.44)$ and previous abortions $(R R R=0.58$, lower use of high FAS dosages among those with previous abortions) were significantly associated with the use of low FAS dosages in the periconceptional period. Unplanned pregnancy ( $R R R=2.66)$, previous abortions $(\mathrm{RRR}=0.68)$ and alcohol intake $(\mathrm{RRR}=1.42)$ were significantly associated with the use of high FAS dosages. These results were homogeneous among study areas $\left(\mathrm{I}^{2}<50 \%\right)$.

The proportion of women using low FAS dosages after the periconceptional period was $55 \%$ and $17 \%$ of women took high FAS dosages after the periconceptional period. In this period, the mean daily intake of FAS was $511.7 \mu \mathrm{g} /$ day for women classified as taking FAS dosages of $400-999 \mu \mathrm{g} /$ day, $59.1 \mu \mathrm{g} /$ day for women taking FAS dosages $<400 \mu \mathrm{g} /$ day and 4095.2 for women taking dosages of $\geq 1000 \mu \mathrm{g} /$ day.

Table 3 shows multivariate analyses for all cohorts combined for the second period (4th-7th month). In the second period, only tobacco smoking was significantly associated with the use of high FAS dosages ( $R R R=0.67)$; no additional significant predictors of the use of low and high FAS dosages were found in the second period.

\section{DISCUSSION}

In this study, we show that a low percentage of pregnant women used FAS in preconception (23\%), although the percentage of use increased to reach most of the women in the third month of pregnancy $(86 \%)$. This pattern was consistent in the four areas of the study, although 
Table 1 Sociodemographic, lifestyle and obstetrics characteristics among pregnant women, from the INMA Project, Spain (2003-2008)

\begin{tabular}{|c|c|c|c|c|c|c|}
\hline & All cohorts $(n=2332)$ & Asturias $(n=434)$ & Guipuzcoa $(n=521)$ & Sabadell $(n=597)$ & Valencia $(n=780)$ & p Value* \\
\hline Maternal age (>30 years), \% (n) & $50.1(1168)$ & $59.7(259)$ & $55.1(287)$ & $47.1(281)$ & $43.2(341)$ & $<0.001$ \\
\hline \multicolumn{7}{|l|}{ Maternal education, $\%(\mathrm{n})$} \\
\hline Primary school or less & $24.0(560)$ & $16.8(73)$ & $11.3(59)$ & $28.0(167)$ & $33.5(261)$ & \multirow[t]{3}{*}{$<0.001$} \\
\hline Secondary school & $41.6(970)$ & $45.2(196)$ & $35.3(184)$ & $42.9(256)$ & $42.8(334)$ & \\
\hline University studies & $34.4(802)$ & $38.0(165)$ & $53.4(278)$ & $29.1(174)$ & $23.7(185)$ & \\
\hline \multicolumn{7}{|l|}{ Paternal education, \% (n) } \\
\hline Primary school or less & 35.5 (829) & $28.8(125)$ & $24.4(127)$ & $36.0(215)$ & 46.4 (362) & \multirow[t]{3}{*}{$<0.001$} \\
\hline Secondary school & $44.5(1037)$ & $49.1(213)$ & $50.5(263)$ & $43.2(258)$ & $38.8(303)$ & \\
\hline University studies & $20.0(466)$ & $22.1(96)$ & $25.1(131)$ & $20.8(124)$ & $14.7(115)$ & \\
\hline $\begin{array}{l}\text { Tobacco smoking (during first } \\
\text { trimester), } \%(\mathrm{n})\end{array}$ & $18.1(423)$ & $17.7(77)$ & $11.9(62)$ & $15.2(91)$ & 24.7 (193) & $<0.001$ \\
\hline $\begin{array}{l}\text { Alcohol intake (during first } \\
\text { trimester), \% (n) }\end{array}$ & $29.9(698)$ & $21.9(95)$ & $36.1(188)$ & 30.0 (179) & $30.3(236)$ & $<0.001$ \\
\hline \multicolumn{7}{|l|}{ Pre-pregnancy BMl in $\mathrm{kg} / \mathrm{m}^{2}, \%(\mathrm{n})$} \\
\hline$<25$ & $73.3(1710)$ & $69.1(300)$ & $80.4(419)$ & $72.2(431)$ & $71.8(560)$ & \multirow[t]{3}{*}{0.001} \\
\hline 25.0-29.9 & $18.7(436)$ & $22.6(98)$ & $14.6(76)$ & $19.6(117)$ & $18.6(145)$ & \\
\hline$\geq 30$ & $8.0(186)$ & $8.3(36)$ & $5.0(26)$ & $8.2(49)$ & $9.6(75)$ & \\
\hline Unplanned pregnancy, n (\%) & $16.7(389)$ & $12.4(54)$ & $9.6(50)$ & $15.6(93)$ & 24.6 (192) & $<0.001$ \\
\hline Parity $(\geq 1), n(\%)$ & $43.3(1009)$ & $38.2(166)$ & $44.9(234)$ & $43.2(258)$ & $45.0(351)$ & 0.112 \\
\hline Previous abortions (yes), n (\%) & $23.5(549)$ & $23.7(103)$ & $20.5(107)$ & $25.5(152)$ & $24.0(187)$ & 0.270 \\
\hline $\begin{array}{l}\text { Private gynaecology (visit during } \\
\text { first trimester), } n(\%)\end{array}$ & $34.2(797)$ & $50.2(218)$ & $26.1(136)$ & $29.5(176)$ & $34.2(267)$ & $<0.001$ \\
\hline $\begin{array}{l}\text { Dietary folate intake in } \mu \mathrm{g} / \text { day } 1 \mathrm{st} \\
\text { period }^{1}, \mathrm{GM} \text { (mean, SD) }\end{array}$ & $293.5(307.8,96.3)$ & $305.0(320.6,103.5)$ & $302.5(314.6,90.3)$ & $285.3(298.2,90.8)$ & $287.6(303.3,99.3)$ & $<0.001$ \\
\hline $\begin{array}{l}\text { Folic acid supplements intake in } \\
\mu \mathrm{g} / \text { day } 1 \text { st period }{ }^{1}, \mathrm{GM} \text { (mean, } \\
\mathrm{SD} \text { ) }\end{array}$ & $450.9(1029.4,1626.6)$ & $610.0(1180.8,1613.0)$ & $585.5(1331.9,1788.1)$ & $353.4(770.6,1401.3)$ & $390.8(941.0,1643.7)$ & $<0.001$ \\
\hline $\begin{array}{l}\text { Dietary folate intake in } \mu \mathrm{g} / \text { day } \\
\text { 2nd period }{ }^{2}, \mathrm{GM} \text { (mean, SD) }\end{array}$ & $290.4(304.7,96.1)$ & $296.2(312.1,100.9)$ & $303.6(313.0,80.2)$ & $289.8(302.4,90.2)$ & $279.2(296.8,106.4)$ & 0.007 \\
\hline $\begin{array}{l}\text { Folic acid supplements intake in } \\
\mu \mathrm{g} / \text { day } 2 \text { nd period }{ }^{2}, \mathrm{GM} \text { (mean, } \\
\mathrm{SD} \text { ) }\end{array}$ & $631.1(870.6,1683.8)$ & $1014.7(1975.2,2267.5)$ & $666.4(541.5,1523.2)$ & $409.3(216.1,843.1)$ & $524.7(977.6,1561.5)$ & $<0.001$ \\
\hline
\end{tabular}




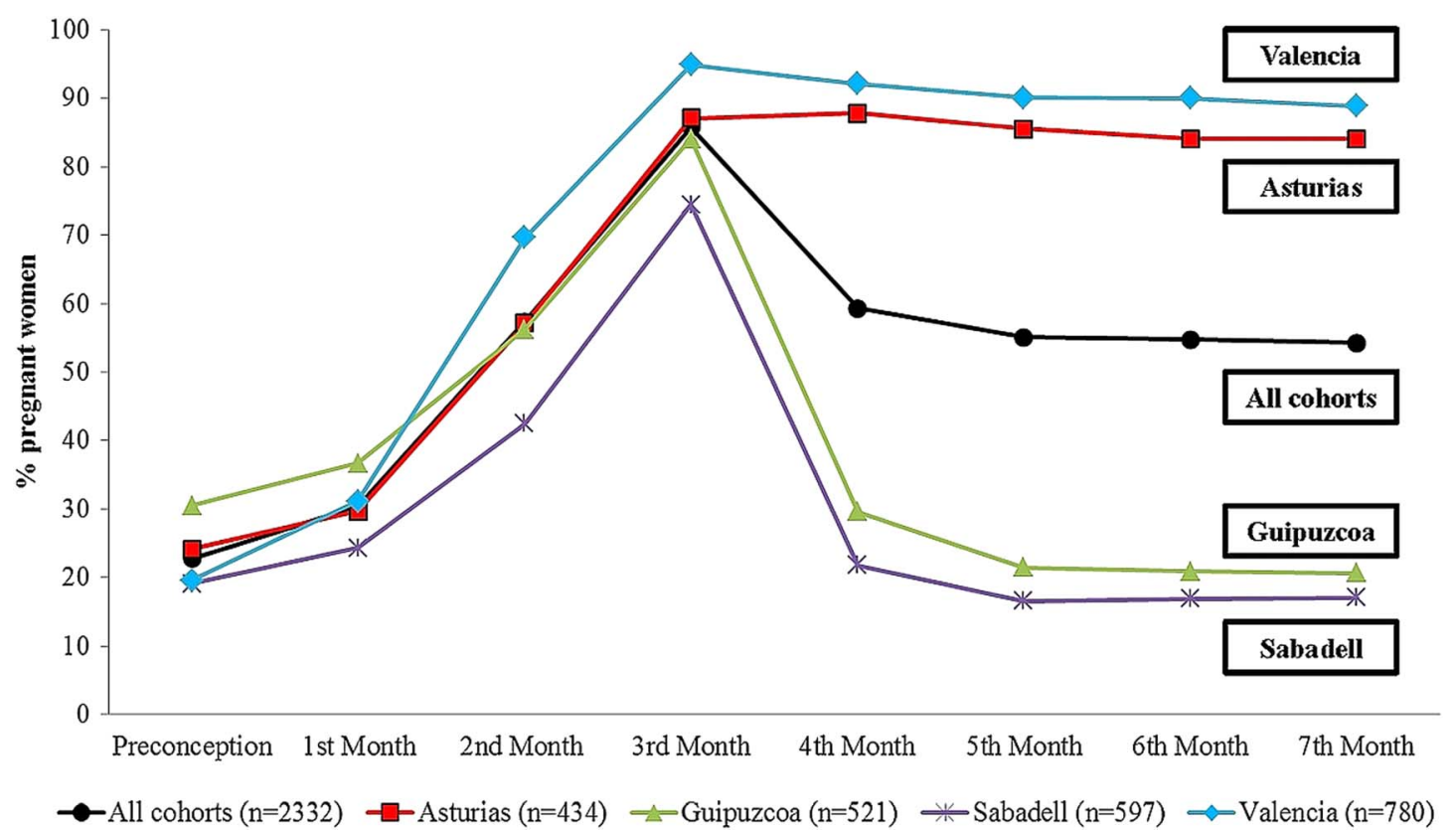

Figure 1 Folic acid supplements use among 2422 participants in all cohorts of the INMA Project, Spain (2003-2008). Percentage by months of pregnancy.

significant differences emerged later; most of the women in Valencia and Asturias continued using FAS after the third month while most of the women in Guipuzcoa and Sabadell stopped using them. We also found that nearly one-third of the women used high dosages of FAS $(\geq 1000 \mu \mathrm{g} /$ day $)$. The use of high FAS dosages in the first period, from preconception to the third month, was significantly associated with unplanned pregnancy and previous spontaneous abortion (lower use of high FAS dosages among those with previous abortions).

The mean daily dietary intake in the present study was similar to that reported in other European studies ${ }^{28-31}$ below the recommended dietary intake for pregnant women. The unsatisfactory intake among pregnant women might be related to the lack of knowledge on food rich in this nutrient, as shown in a study conducted in a Mediterranean population, in which only $40 \%$ of respondents could identify one food rich in folate. ${ }^{32}$ Regarding the use of FAS, the results of this study are in accordance with previous studies conducted in Spain and Portugal, where around $70 \%$ of pregnant women did not take FAS before pregnancy, ${ }^{31} 3334$ and slightly higher than in other European studies. ${ }^{17-20} 30$ The considerable number of women who did not use FAS may be explained in part by the fact that they were not aware of being pregnant and, therefore, were not informed of the benefits of FAS at the beginning of their pregnancy. Based on our results, it seems that when women are aware of their pregnancy, they increase their use of FAS, particularly in the second and third month of pregnancy.

We observed two different patterns of FAS use after the third month in the four geographical areas of the study. Women in Valencia and Asturias continued with the use of FAS while women in Guipuzcoa and Sabadell mostly abandoned the use of supplements. We have no clear explanation for the two different patterns of FAS use observed between areas, although it could be related, in part, to the different policy statements of regional scientific societies about FAS use, as has been observed for other nutrients such as iodine supplementation. ${ }^{35}$

The large number of pregnant women reporting the use of high FAS dosages during pregnancy has also been reported in two other previous studies in Spain. ${ }^{16} 36 \mathrm{~A}$ possible cause could be related to medical reasons since women with diabetes, epilepsy or history of NTDs before pregnancy are usually recommended to take FAS dosages of $5000 \mu \mathrm{g} /$ day in the periconceptional period. However, in our study, the number of women with these pathologies was low $(<1 \%)$. Moreover, the use of these high dosages of FAS was unnecessarily maintained after the third month of pregnancy. The percentage of women taking high dosages of FAS in this study was lower than that observed in a previous study in Spain, ${ }^{16}$ which may be explained in part by the debate and the controversy on the consequences of a higher than recommended FA supplementation. ${ }^{37-39}$ We believe that the percentage of women taking high FAS dosages still remains high, and further studies are needed to monitor the use of FAS during pregnancy and the potential harmful effects that have been shown recently. ${ }^{5-8}$

Several associations were found with the use of high FAS dosages. The positive association with unplanned pregnancy and the negative association with previous spontaneous abortion have been found in other 
Table 2 Pooled $\mathrm{RRR}^{\star}$ and $95 \% \mathrm{Cl}$ of folic acid supplement doses in the periconceptional period (first period) $\dagger$ of pregnancy among pregnant women, from the INMA Project, Spain (2003-2008)

\begin{tabular}{|c|c|c|c|c|c|c|c|}
\hline \multirow{4}{*}{$\begin{array}{l}\text { Women who took } \\
\text { FAS, n (\%) }\end{array}$} & \multicolumn{7}{|c|}{ Folic acid supplement use (in $\mu \mathrm{g} /$ day) during the first period $\dagger$} \\
\hline & \multirow{3}{*}{$\begin{array}{l}\begin{array}{l}400-999 \\
(\text { mean=433.0) } \\
329(14 \%) \\
n\end{array} \\
\end{array}$} & \multirow{2}{*}{\multicolumn{3}{|c|}{$\begin{array}{l}<400, \text { included non use } \\
(\text { mean }=141.8)\end{array}$}} & \multirow{2}{*}{\multicolumn{3}{|c|}{$\begin{array}{l}\geq 1000(\text { mean=3104.6) } \\
666(29 \%)\end{array}$}} \\
\hline & & & & & & & \\
\hline & & $\mathbf{n}$ & $\mathrm{RRR}^{\star}(95 \% \mathrm{Cl})$ & $I^{2}, \% \ddagger$ & $\mathbf{n}$ & $\operatorname{RRR}^{\star}(95 \% \mathrm{Cl})$ & $1^{2}, \% \neq$ \\
\hline \multicolumn{8}{|l|}{ Maternal age, (years) } \\
\hline$\leq 30$ & 161 & 722 & 1.00 & & 281 & 1.00 & \\
\hline$>30$ & 168 & 614 & $0.90(0.58$ to 1.40$)$ & 58.4 & 385 & 1.31 (0.82 to 2.10$)$ & 58.5 \\
\hline \multicolumn{8}{|l|}{ Maternal education } \\
\hline Primary school or less & 65 & 373 & 1.00 & & 122 & 1.00 & \\
\hline Secondary school & 124 & 563 & $1.06(0.73$ to 1.52$)$ & 0.0 & 283 & $1.31(0.88$ to 1.94$)$ & 0.0 \\
\hline University studies & 140 & 400 & 0.66 (0.44 to 0.98$)$ & 27.3 & 261 & $0.91(0.59$ to 1.39$)$ & 24.4 \\
\hline \multicolumn{8}{|l|}{ Paternal education } \\
\hline Primary school or less & 96 & 525 & 1.00 & & 208 & 1.00 & \\
\hline Secondary school & 164 & 557 & $0.70(0.51$ to 0.95$)$ & 0.0 & 316 & $0.82(0.59$ to 1.15$)$ & 0.0 \\
\hline University studies & 69 & 254 & 0.97 (0.65 to 1.45$)$ & 0.0 & 142 & $1.00(0.65$ to 1.54$)$ & 0.0 \\
\hline \multicolumn{8}{|l|}{ Tobacco smoking } \\
\hline No & 289 & 1061 & 1.00 & & 558 & 1.00 & \\
\hline Yes & 40 & 275 & 1.63 (1.11 to 2.39$)$ & 0.0 & 108 & $1.36(0.90$ to 2.07$)$ & 0.0 \\
\hline \multicolumn{8}{|l|}{ Alcohol consumption $†$} \\
\hline No & 251 & 923 & 1.00 & & 460 & 1.00 & \\
\hline Yes & 78 & 413 & 1.40 (1.02 to 1.92$)$ & 39.1 & 206 & $1.42(1.01$ to 1.98$)$ & 19.2 \\
\hline \multicolumn{8}{|l|}{ Pre-pregnancy BMI } \\
\hline$<25$ & 241 & 969 & 1.00 & & 499 & 1.00 & \\
\hline $25-29.9$ & 60 & 253 & 0.95 (0.67 to 1.33$)$ & 0.0 & 123 & 0.90 (0.62 to 1.30$)$ & 19.9 \\
\hline$\geq 30$ & 28 & 114 & $0.89(0.55$ to 1.44$)$ & 12.4 & 44 & $0.79(0.46$ to 1.36$)$ & 0.0 \\
\hline \multicolumn{8}{|l|}{ Planned pregnancy } \\
\hline Yes & 312 & 1051 & 1.00 & & 579 & 1.00 & \\
\hline No & 17 & 285 & 4.20 (2.47 to 7.12$)$ & 5.0 & 87 & 2.66 (1.52 to 4.65$)$ & 0.0 \\
\hline \multicolumn{8}{|l|}{ Parity } \\
\hline 0 & 209 & 744 & 1.00 & & 369 & 1.00 & \\
\hline$\geq 1$ & 120 & 592 & 1.44 (1.08 to 1.91$)$ & 0.0 & 297 & 1.33 (0.98 to 1.80$)$ & 0.0 \\
\hline \multicolumn{8}{|l|}{ Previous abortions } \\
\hline No & 231 & 1047 & 1.00 & & 504 & 1.00 & \\
\hline Yes & 98 & 289 & $0.58(0.43$ to 0.77$)$ & 45.5 & 162 & $0.68(0.50$ to 0.94$)$ & 42.0 \\
\hline \multicolumn{8}{|l|}{ Private gynaecologist } \\
\hline No & 189 & 923 & 1.00 & & 423 & 1.00 & \\
\hline Yes & 140 & 413 & $0.78(0.52$ to 1.17$)$ & 53.0 & 243 & $0.88(0.42$ to 1.88$)$ & $84.2 \S$ \\
\hline $\begin{array}{l}{ }^{*} \text { Cohort-specific multinomial } \\
\text { †During the periconceptional } \\
\text { †We used the results from fix } \\
>50 \% \text {. } \\
\text { \$P Cochran }<0.05 \text { from test } \\
\text { BMl, body mass index; RRR }\end{array}$ & $\begin{array}{l}\text { stic models were } \\
\text { ge from the prec } \\
\text { effect meta-anal } \\
\text { eterogeneity. }\end{array}$ & $\begin{array}{l}\text { bined } \\
\text { ption t } \\
\text { nodel }\end{array}$ & $\begin{array}{l}\text { ing meta-analysis, the } n \\
\text { he third month. } \\
\text { len } \mathrm{I}^{2} \text { was }<50 \% \text { and frc }\end{array}$ & the ral & effe & $\begin{array}{l}\text { y all variables in the ta } \\
\text { meta-analysis model w }\end{array}$ & $I^{2}$ was \\
\hline
\end{tabular}

studies. ${ }^{17} 1920 \quad 40-43$ Women who have planned their pregnancy and those who had undergone a previous spontaneous abortion may have higher awareness of the benefits of recommended intake and FAS dosages (400$999 \mu \mathrm{g} /$ day) in pregnancy. The association with tobacco smoking, alcohol intake and parity found in our study have also been found in other studies. ${ }^{19} 4243$ It is possible that pregnant women with better lifestyles had a better compliance with the recommended dosages of FAS than those with less healthy lifestyles (eg, alcohol drinkers). However, more studies are required to confirm these associations with the use of high dosages of FAS during the periconceptional period in order to implement public health actions.

This study has several strengths. The prospective design minimises selection and recall bias. We assessed dietary folate intake and FAS use prospectively in different geographical areas of Spain with a wide range of consumption, using a validated FFQ in the same study population. Our study also has some limitations. This was a population-based cohort study and nonparticipation might limit the generalisability of some results; however, when the sociodemographic characteristics of participants and non-participants were 
Table 3 Pooled RRR ${ }^{*}$ and $95 \% \mathrm{Cl}$ of folic acid supplements doses in the second period $\dagger$ of pregnancy among pregnant women, from the INMA Project, Spain (2003-2008)

\begin{tabular}{|c|c|c|c|c|c|c|c|}
\hline \multirow{4}{*}{$\begin{array}{l}\text { Women who took FAS, } \\
\text { n (\%) }\end{array}$} & \multicolumn{7}{|c|}{ Folic acid supplement use (in $\mu \mathrm{g} /$ day) during the second period $\dagger$} \\
\hline & \multirow{3}{*}{$\begin{array}{l}400-999 \\
(m e a n=511.7) \\
657(28 \%) \\
n\end{array}$} & \multirow{2}{*}{\multicolumn{3}{|c|}{$\begin{array}{l}<400, \text { included non use } \\
\text { (mean }=59.1) \\
1275(55 \%)\end{array}$}} & \multirow{2}{*}{\multicolumn{3}{|c|}{$\begin{array}{l}\geq 1000(\text { mean=4095.2) } \\
394(17 \%)\end{array}$}} \\
\hline & & & & & & & \\
\hline & & $\mathbf{n}$ & $\mathrm{RRR}^{\star}(95 \% \mathrm{Cl})$ & $I^{2}(\%) \neq$ & $\bar{n}$ & RRR $^{*}(95 \% \mathrm{Cl})$ & $I^{2}(\%) \ddagger$ \\
\hline \multicolumn{8}{|l|}{ Maternal age (years) } \\
\hline$\leq 30$ & 343 & 653 & 1.00 & & 164 & 1.00 & \\
\hline$>30$ & 314 & 622 & 1.05 (0.61 to 1.82$)$ & $77.2 \S$ & 230 & 1.54 (0.92 to 2.59$)$ & $61.8 \S$ \\
\hline \multicolumn{8}{|l|}{ Maternal education } \\
\hline Primary school or less & 194 & 284 & 1.00 & & 82 & 1.00 & \\
\hline Secondary school & 274 & 523 & 1.29 (0.97 to 1.72$)$ & 0.0 & 168 & $1.26(0.88$ to 1.80$)$ & 0.0 \\
\hline University studies & 189 & 468 & $1.30(0.92$ to 1.85$)$ & 0.0 & 144 & 1.20 (0.54 to 2.66$)$ & $65.4 \S$ \\
\hline \multicolumn{8}{|l|}{ Paternal education } \\
\hline Primary school or less & 254 & 441 & 1.00 & & 133 & 1.00 & \\
\hline Secondary school & 282 & 568 & 0.89 (0.69 to 1.15$)$ & 0.0 & 182 & 0.94 (0.68 to 1.29$)$ & 0.0 \\
\hline University studies & 121 & 266 & 0.78 (0.54 to 1.12$)$ & 0.0 & 79 & 0.80 (0.52 to 1.22$)$ & 25.3 \\
\hline \multicolumn{8}{|l|}{ Tobacco smoking } \\
\hline No & 512 & 1088 & 1.00 & & 332 & 1.00 & \\
\hline Yes & 145 & 187 & 0.70 (0.42 to 1.18$)$ & $61.7 \rrbracket$ & 62 & 0.67 (0.47 to 0.96$)$ & 8.1 \\
\hline \multicolumn{8}{|l|}{ Alcohol consumption $\dagger$} \\
\hline No & 426 & 767 & 1.00 & & 252 & 1.00 & \\
\hline Yes & 231 & 508 & $1.01(0.80,1.28)$ & 0.0 & 142 & $1.09(0.82$ to 1.45$)$ & 0.0 \\
\hline \multicolumn{8}{|l|}{ Pre-pregnancy BMI } \\
\hline$<25$ & 456 & 970 & 1.00 & & 281 & 1.00 & \\
\hline $25-29.9$ & 138 & 217 & 0.82 (0.62 to 1.09$)$ & 0.0 & 80 & 0.89 (0.63 to 1.25$)$ & 0.0 \\
\hline$\geq 30$ & 63 & 88 & 0.70 (0.47 to 1.06$)$ & 11.5 & 33 & 0.87 (0.53 to 1.43$)$ & 0.0 \\
\hline \multicolumn{8}{|l|}{ Planned pregnancy } \\
\hline Yes & 531 & 1073 & 1.00 & & 336 & 1.00 & \\
\hline No & 126 & 202 & $1.05(0.78$ to 1.41$)$ & 0.0 & 58 & 0.90 (0.61 to 1.32$)$ & 0.0 \\
\hline \multicolumn{8}{|l|}{ Parity } \\
\hline 0 & 381 & 717 & 1.00 & & 223 & 1.00 & \\
\hline$\geq 1$ & 276 & 558 & $1.08(0.85$ to 1.38$)$ & 35.5 & 171 & 0.99 (0.74 to 1.33$)$ & $76.3 \S$ \\
\hline \multicolumn{8}{|l|}{ Previous abortions } \\
\hline No & 504 & 974 & 1.00 & & 301 & 1.00 & \\
\hline Yes & 153 & 301 & 1.07 (0.82 to 1.41$)$ & 7.8 & 93 & 0.95 (0.69 to 1.31$)$ & 10.9 \\
\hline \multicolumn{8}{|l|}{ Private gynaecologist } \\
\hline No & 404 & 880 & 1.00 & & 245 & 1.00 & \\
\hline Yes & 253 & 395 & 0.88 (0.60 to 1.27$)$ & 54.9 & 149 & 0.79 (0.28 to 2.21$)$ & $91.3 \S$ \\
\hline
\end{tabular}

compared, no significant differences were found except for working status and age, with a higher proportion of working women and slightly higher mean age among participants. Despite some study limitations, if confirmed, our findings should have implications for future public health policies and strategies to promote adequate use of FAS at the recommended dosages during the periconceptional period, and to prevent the use of unnecessary dosages in other periods.

In conclusion, this study shows that the use of FAS among pregnant women in Spain is far from satisfactory. Most women did not follow recommendations for FAS during pregnancy, using dosages either below or above the current recommendation. Previous pregnancies, tobacco smoking, alcohol consumption, unplanned pregnancies and no previous abortions were associated with FAS use below $400 \mu \mathrm{g} /$ day in the periconceptional period. Alcohol consumption, unplanned pregnancy and previous spontaneous abortion were also predictors of the use of high dosages of FAS at this initial stage. These findings should be further monitored; meanwhile, public health strategies should be planned to increase public awareness of the appropriate periconceptional use of FAS and to encourage health professionals to prevent the use of FAS dosages above or below the current recommendations. 
Author affiliations

${ }^{1}$ Departamento Salud Pública, Universidad Miguel Hernández, San Juan de Alicante, Spain

${ }^{2}$ CIBER de Epidemiología y Salud Pública (CIBERESP), Spain

${ }^{3}$ Centre for Research in Environmental Epidemiology (CREAL), Barcelona, Spain

${ }^{4}$ Servicio de Pediatria, Hospital San Agustin-Aviles, Asturias, Spain

${ }^{5}$ Universidad de Oviedo, Asturias, Spain

${ }^{6}$ Subdirección de Salud Pública y Adicciones de Gipuzkoa, San Sebastian, Spain

${ }^{7}$ Instituto de Investigación Sanitaria BIODONOSTIA, San Sebastián, Spain

${ }^{8}$ Foundation for the Promotion of Health and Biomedical Research in the Valencian Region (FISABIO/CSISP), Public Health, Valencia, Spain

${ }^{9}$ Departamento de Medicina, Universitat Jaume I, Castellón de la Olana, Spain

Twitter Follow Eva María Navarrete-Muñoz at @emnavarretem

Acknowledgements The authors appreciate the English revisions made by Mr Jonathan Whitehead.

Collaborators For a complete list of INMA project researchers: http://www. proyectoinma.org/presentacion-inma/listado-investigadores/en_ listado-investigadores.html.

Contributors EMN-M and JV conceived the study. EMN-M, DV-G and JV conducted the data analysis and prepared the manuscript; MGdIH contributed to the conceptual approach and manuscript preparation; MM, IR, EM and LS-M contributed to the data interpretation and manuscript preparation; DG-M and MGdIH assisted with the nutritional data and provided feedback; JV designed the FFQ and contributed to manuscript preparation; JJ, Jl, AT, MR and JV supervised the data collection, obtained funding, and helped with data interpretation and manuscript preparation. EMN-M, DV-G, MGdIH, DG-M, EM, $\mathrm{JJ}, \mathrm{IR}, \mathrm{AT}, \mathrm{JI}, \mathrm{LS}-\mathrm{M}, \mathrm{MR}$ and JV were responsible for critical revision of the manuscript for important intellectual content.

Funding This study was funded by grants from Instituto de Salud Carlos III and Spanish Ministry of Health (Red INMA G03/176; CB06/02/0041; FIS 97/ 0588; 00/0021-2, PI061756; PS0901958; FIS-FEDER 03/1615, 04/1509, 04/ 1112, 04/1931, 05/1079, 05/1052, 06/1213, 07/0314; 09/02647; FIS-PI041436, FIS-PI081151, FIS-PI06/0867; FIS-PS09/00090, FIS-PI042018, FIS-PI09 02311, FIS PI11/01007, FISPI13/02429) Universidad de Oviedo, Conselleria de Sanitat Generalitat Valenciana, Generalitat de Catalunya-CIRIT 1999SGR 00241, Department of Health of the Basque Government (2005111093 and 2009111069) and the Provincial Government of Guipuzcoa (DFG06/004 and DFG08/001).

\section{Competing interests None declared.}

Patient consent Obtained.

Ethics approval This study was conducted with the approval of the The Institut Municipal d'Investigació Mèdica (Barcelona), the Asturian Regional Ethics Committee (Asturias), Hospital La Fe (Valencia) and Hospital Donostia (Gipuzkoa)

Provenance and peer review Not commissioned; externally peer reviewed.

Data sharing statement No additional data are available.

Open Access This is an Open Access article distributed in accordance with the Creative Commons Attribution Non Commercial (CC BY-NC 4.0) license, which permits others to distribute, remix, adapt, build upon this work noncommercially, and license their derivative works on different terms, provided the original work is properly cited and the use is non-commercial. See: http:// creativecommons.org/licenses/by-nc/4.0/

\section{REFERENCES}

1. MRC Vitamin Study Research Group. Prevention of neural tube defects: results of the Medical Research Council Vitamin Study. Lancet 1991;338:131-7.

2. Czeizel AE, Dudás I. Prevention of the first occurrence of neural-tube defects by periconceptional vitamin supplementation. N Engl J Med 1992;327:1832-5.
3. Food and Nutrition Board, Institute of Medicine. Dietary reference intakes for thiamin, riboflavin, niacin, vitamin B6, folate, vitamin B12, pantothenic acid, biotin, and choline. Washington DC: The National Academies Press, 1998.

4. Grupo de trabajo de la Guía de práctica clínica de atención en el embarazo y puerperio. Ministerio de Sanidad, Servicios Sociales e Igualdad. Agencia de Evaluación de Tecnologías Sanitarias de Andalucía. 2014, Guías de Práctica Clínica en el SNS: AETSA 2011/10. http://www.juntadeandalucia.es/salud/servicios/contenidos/ nuevaaetsa/up/AETSA 2011 10 GPC Embarazo.pdf (accessed Jul 2014).

5. Pastor-Valero M, Navarrete-Muñoz EM, Rebagliato M, et al. Periconceptional folic acid supplementation and anthropometric measures at birth in a cohort of pregnant women in Valencia, Spain. Br J Nutr 2011;105:1352-60.

6. Takimoto H, Hayashi F, Kusama K, et al. Elevated maternal serum folate in the third trimester and reduced fetal growth: a longitudinal study. J Nutr Sci Vitaminol 2011;57:130-7.

7. Zetstra-van der Woude PA, De Walle HEK, Hoek A, et al. Maternal high-dose folic acid during pregnancy and asthma medication in the offspring. Pharmacoepidemiol Drug Saf 2014;23:1059-65.

8. Valera-Gran D, García de la Hera M, Navarrete-Muñoz EM, et al. Folic Acid supplements during pregnancy and child psychomotor development after the first year of life. JAMA Pediatr 2014;168: e142611.

9. Vollset SE, Clarke R, Lewington S, et al. Effects of folic acid supplementation on overall and site-specific cancer incidence during the randomised trials: meta-analyses of data on 50,000 individuals. Lancet 2013;381:1029-36.

10. Tamura T, Picciano MF. Folate and human reproduction. Am J Clin Nutr 2006;83:993-1016.

11. Mantovani E, Filippini F, Bortolus R, et al. Folic acid supplementation and preterm birth: results from observational studies. BioMed Res Int 2014;481914.

12. Roth $\mathrm{C}$, Magnus $\mathrm{P}$, Schjølberg $\mathrm{S}$, et al. Folic acid supplements in pregnancy and severe language delay in children. JAMA 2011;306:1566-73.

13. Surén $\mathrm{P}$, Roth $\mathrm{C}$, Bresnahan $\mathrm{M}$, et al. Association between materna use of folic acid supplements and risk of autism spectrum disorders in children. JAMA 2013;309:570-7.

14. Brown SB, Reeves KW, Bertone-Johnson ER. Maternal folate exposure in pregnancy and childhood asthma and allergy: a systematic review. Nutr Rev 2014;72:55-64.

15. Crider KS, Cordero AM, Qi YP et al. Prenatal folic acid and risk of asthma in children: a systematic review and meta-analysis. $A m \mathrm{~J}$ Clin Nutr 2013;98:1272-81.

16. Martínez-Frías ML. Grupo de trabajo del ECEMC [folic acid dose in the prevention of congenital defects]. Med Clin (Barc) 2007;128:609-16.

17. Timmermans S, Jaddoe VWV, Mackenbach JP, et al. Determinants of folic acid use in early pregnancy in a multi-ethnic urban population in the Netherlands: the Generation R study. Prev Med 2008;47:427-32.

18. Paulik E, Császár J, Kozinszky Z, et al. Preconceptional and prenatal predictors of folic acid intake in Hungarian pregnant women. Eur J Obstet Gynecol Reprod Biol 2009;145:49-52.

19. Cueto HT, Riis AH, Hatch E, et al. Predictors of preconceptional folic acid or multivitamin supplement use: a cross-sectional study of Danish pregnancy planners. Clin Epidemiol 2012;4:259-65.

20. Nilsen RM, Vollset SE, Gjessing HK, et al. Patterns and predictors of folic acid supplement use among pregnant women: the Norwegian Mother and Child Cohort Study. Am J Clin Nutr 2006;84:1134-41.

21. Guxens M, Ballester F, Espada M, et al. Cohort profile: the INMA--INfancia y Medio Ambiente--(Environment and Childhood) Project. Int J Epidemiol 2012;41:930-40.

22. Navarrete-Muñoz EM, Giménez Monzó D, García de La Hera M, et a/[Folic acid intake from diet and supplements in a population of pregnant women in Valencia, Spain]. Med Clin (Barc) 2010;135:637-43.

23. Willett WC, Sampson L, Stampfer MJ, et al. Reproducibility and validity of a semiquantitative food frequency questionnaire. $A m \mathrm{~J}$ Epidemiol 1985;122:51-65.

24. Vioque J, Navarrete-Muñoz EM, Gimenez-Monzó D, et al. Reproducibility and validity of a food frequency questionnaire among pregnant women in a Mediterranean area. Nutr $J$ 2013;12:26.

25. US Department of Agriculture, Agricultural Research Service. USDA National Nutrient Database for Standard Reference, Release 21. http://www.nal.usda.gov/fnic/foodcomp/Data/SR21/nutrlist/sr21a306. pdf (accessed Nov 2008). 
26. Palma I, Farran A, Cantós D. Tablas de Composición de Alimentos por Medidas Caseras de Consumo Habitual en España. CESNID. Madrid: McGraw-Hill Interamerican, 2008.

27. Higgins JPT, Thompson SG, Deeks JJ, et al. Measuring inconsistency in meta-analyses. BMJ 2003;327:557-60.

28. Rogers I, Emmett P. Diet during pregnancy in a population of pregnant women in South West England. ALSPAC Study Team. Avon Longitudinal Study of Pregnancy and Childhood. Eur J Clin Nutr 1998;52:246-50.

29. Erkkola M, Karppinen M, Järvinen A, et al. Folate, vitamin D, and iron intakes are low among pregnant Finnish women. Eur J Clin Nutr 1998;52:742-8.

30. Mouratidou T, Ford F, Prountzou F, et al. Dietary assessment of a population of pregnant women in Sheffield, UK. Br J Nutr 2006;96:929-35.

31. Pinto $\mathrm{E}$, Barros $\mathrm{H}$, dos Santos Silva I. Dietary intake and nutritional adequacy prior to conception and during pregnancy: a follow-up study in the north of Portugal. Public Health Nutr 2009;12:922-31.

32. Coll O, Pisa S, Palacio M, et al. Awareness of the use of folic acid to prevent neural tube defects in a Mediterranean area. Eur $\mathrm{J}$ Obstet Gynecol Reprod Biol 2004;115:173-7.

33. Martínez-Frías ML, Rodríguez-Pinilla E, Bermejo E. [Analysis of the Spanish situation regarding folic acid/calcic folinate consumption for birth defects prevention]. Med Clin (Barc) 2003;121:772-5.

34. Cuervo M, Sayon-Orea C, Santiago S, et al. Dietary and health profiles of Spanish women in preconception, pregnancy and lactation. Nutrients 2014;6:4434-51.
35. Donnay S, Arena J, Lucas A, et al. Position statement of the working group on disorders related to iodine deficiency and thyroid dysfunction of the Spanish Society of Endocrinology and Nutrition. Endocrinol Nutr 2014;61:27-34.

36. Sanfélix-Gimeno G, Ferreros I, Librero J, et al. Characterization of folate supplementation in pregnancy, based on a combination of health information systems. Gac Sanit 2012;26:512-18.

37. Lucock M. Folic acid: nutritional biochemistry, molecular biology, and role in disease processes. Mol Genet Metab 2000;71:121-38.

38. Martínez-Frías ML, Rodríguez-Pinilla E, Mejías C, et al. Primary prevention of neural tube defects: folic acid or levofoline acid? Med Clin (Barc) 2002;118:358-9.

39. Lucock M. Is folic acid the ultimate functional food component for disease prevention? BMJ 2004;328:211-14.

40. Morin $\mathrm{P}$, De Wals $\mathrm{P}$, Noiseux $\mathrm{M}$, et al. Pregnancy planning and folic acid supplement use: results from a survey in Quebec. Prev Med 2002;35:143-9.

41. Morin P, De Wals P, St-Cyr-Tribble D, et al. Pregnancy planning: a determinant of folic acid supplements use for the primary prevention of neural tube defects. Can J Public Health Rev 2002;93:259-63.

42. Braekke K, Staff AC. Periconceptional use of folic acid supplements in Oslo. Acta Obstet Gynecol Scand 2003;82:620-7.

43. Knudsen VK, Orozova-Bekkevold I, Rasmussen LB, et al. Low compliance with recommendations on folic acid use in relation to pregnancy: is there a need for fortification? Public Health Nutr $2004 ; 7: 843-50$ 